Res Publica. Revista de Historia de las Ideas Políticas ISSN: $1576-4184$

http://dx.doi.org/10.5209/RPUB.57499

\title{
La arquitectura teatral griega constituye una analogía del cuerpo humano cósmico y político
}

\author{
Juan Antonio Roche Cárcel*
}

Recibido: 20 de enero de 2017 / Aceptado: 14 de julio de 2017

Resumen. En este artículo, la arquitectura teatral de la Grecia Antigua va a ser considerada como un cuerpo-signo que significa, construido social, cultural y políticamente, como un reflejo y creador del orden social, como un cuerpo que es civilización y, por consiguiente, como un microcosmos de la concepción del mundo de los griegos antiguos. Y es que la arquitectura teatral es vista por los helenos como un cuerpo articulador, delimitado, diferenciado y separado y con entradas o salidas que comunican sus funciones interiores con las exteriores, por lo que, a pesar de su autonomía, no está aislado en sí mismo, sino que constituye una auténtica red de relaciones entre el universo teatral, la polis y el mundo.

Palabras clave: Sociología del Cuerpo; Sociología Histórica; Grecia Antigua; arquitectura teatral.

\section{[en] The Greek Theatrical Architecture Constitutes an Analogy of the Cosmic and Political Human Body}

\begin{abstract}
In this article, the theatrical architecture of Ancient Greece is to be considered as a body-sign that means, socially, culturally and politically constructed, as a reflection and creator of the social order, as a body that is civilization and, consequently, as a microcosm of the worldview of the ancient Greeks. And it is that the theatrical architecture is seen by the Hellenes as an articulating body, delimited, differentiated and separated and with entrances or exits that communicate their interior functions with the external ones, reason why, in spite of its autonomy, it is not isolated in itself but it constitutes a true network of relations between the theatrical universe, the polis and the world.
\end{abstract}

Keywords: Sociology of the Body; Historical Sociology; Ancient Greece; theater architecture.

Sumario: 1. Introducción. 2. En Grecia, los cuerpos humanos están articulados con el mundo. 2.1. El cuerpo humano está articulado y conforma una red de relaciones con la naturaleza, los dioses y la polis. 2.2. El cuerpo masculino, desnudo, y, el femenino, velado. 2.3. El cuerpo y los sentidos. 3. La arquitectura teatral griega constituye una analogía del cuerpo humano político. 3.1. Edificio teatral representa un cuerpo articulado, cósmico, masculino y femenino que ve, oye y habla. 3.2. La arquitectura teatral simboliza la triple geografía del cuerpo humano. 4. A modo de conclusiones.

Cómo citar: Roche Cárcel, J. A. (2017). La arquitectura teatral griega constituye una analogía del cuerpo humano cósmico y político, en Res publica 20.3, 521-543.

Universidad de Alicante

ja.roche@ua.es 


\section{Introducción}

En general, la mirada moderna ha distinguido la dimensión simbólica Leib -el cuerpo cultural- de la dimensión física Körper -el cuerpo anatómico- ${ }^{1}$, ha separado el cuerpo de la mente, ha enfrentado lo material con lo cultural, ha contrapuesto la acción con la estructura ${ }^{2} \mathrm{y}$ ha considerado a la mujer como cuerpo y al hombre como mente. Pero, con Nietzsche, con Foucault, con la teoría feminista (Simone de Beauvoir, Luce Irigaray y Julia Kristeva) y con la crítica posmoderna del proyecto racional, esta forma de ver el cuerpo se ha ido deconstruyendo, especialmente en lo que se refiere a la centralidad corporal masculina ${ }^{3}$. Ello nos ha obligado a repensar el cuerpo en nuestras complejas sociedades ${ }^{4} \mathrm{y}$ a considerarlo $-\mathrm{y}$ en esto coinciden la Sociología y la Historia- como la metáfora central del orden político y social ${ }^{5}$.

Ante todo, porque el cuerpo es construido socialmente ${ }^{6}$, es decir, que pertenece a la cultura y no a una identidad biológica ${ }^{7} \mathrm{o}$, al menos, en una gran parte, y también porque es un lugar de poder ${ }^{8}$. En efecto, a partir de Foucault, lo que interesa sobre todo son los efectos del poder sobre el cuerpo, entendido como un espacio de dominio, de control y de opresión, al tiempo que como el foco de resistencia a ese poder'. En paralelo, hoy cabe reflexionar acerca del mundo y del vínculo social que establece el cuerpo, pues sus límites diseñan, a su manera, el orden moral y significativo de ese mundo, de modo que cualquier perturbación que se produzca en la configuración del cuerpo supone, al mismo tiempo, el desorden en la coherencia de la cosmovisión ${ }^{10}$. En este sentido, cabe tener presente que el cuerpo es, al mismo tiempo, un reflejo y un constituyente del orden social y que de lo que se trata-como nos sugiere la Antropología- es de dar con la "civilización del cuerpo", asimilando éste no de un modo aislado sino como una prolongación simbólica y como un objeto de presentación y de representación y sustituyendo, así, el cuerpo-objeto de la ciencia-biomédica- por el cuerpo-signo que significa ${ }^{11}$.

Pero conviene anticipar que, en la cosmovisión helena, aunque se prefigura la lógica disyuntiva moderna del cuerpo-envoltura que enfrenta sobre todo a lo interno con lo externo y, más tímidamente, al propio interior, lo que predomina es una concepción del cuerpo articuladora que junta y no descompone. Cierto, Grecia observa el cuerpo como perfectamente delimitado, diferenciado y separado, con una parte

J. Planella, "Corpografías: dar la palabra al cuerpo", en Artnodes. Revista de intersecciones entre artes, ciencias y tecnologias, $\mathrm{n}^{\circ} .6,2006$, p. 13.

J. García Selgas, "El "cuerpo" como base del sentido de la acción", en REIS, n 68, Centro de Investigaciones Sociológicas, Madrid, 1994, p. 45.

3 B. S. Turner, "Los avances recientes en la teoría del cuerpo", en REIS, 68, 1994, pp. 17-29; A. Buñuel Heras, "La construcción social del cuerpo de la mujer en el deporte", en REIS, 68, 1995, pp. 97-100.

J. Planella, op. cit., p. 20.

B. S. Turner, op. cit., p. 14.

L. Salinas, "La construcción social del cuerpo", en REIS, 68, 1994, p. 95.

A. Martínez Barreiro, "La construcción social del cuerpo en las sociedades contemporáneas", en PAPERS. Revista de Sociología, no 73, Universitat de Barcelona, 2004, p. 128.

A. Buñuel, op. cit., pp. 101-106.

J. Planella, op. cit., pp. 14-18.

10 D. Le Breton, "Lo imaginario del cuerpo en la tecnociencia", en REIS, $\mathrm{n}^{\circ} 68$, Centro de Investigaciones Sociológicas, Madrid, 1994, p. 209.

11 M. J. Devillard, "De los discursos antropológicos sobre naturaleza, cuerpo y cultura", en Política y Sociedad, vol. 39, nº 3, Universidad Complutense, Madrid, 2002, pp. 599-609. 
interior y otra exterior, pero con orificios para que ambas se comuniquen. Por consiguiente, no está encerrado, enclaustrado o aislado en sí mismo, sino que resulta permeable a las fuerzas que lo animan, a la intrusión de potencias vitales que puedan agitarle. No extrañe que el individuo configure un universo mundano autónomo que desconoce la subordinación y el enfrentamiento con lo sobrenatural y que se caracteriza, esencialmente, por la movilidad, por constituir una red de relaciones, así como por estar vivo, esto es, por mantener las articulaciones en funcionamiento. En suma, revelador del carácter articulador del cuerpo heleno, es que el individuo y sus funciones mentales se representen de un modo relacional, vinculándose con los otros, con las situaciones y, en definitiva, con el mundo.

Por consiguiente, en este artículo, la arquitectura teatral de la Grecia Antigua va a ser considerada como un cuerpo-signo que significa, construido social, cultural y políticamente, como un reflejo y creador del orden social, como un cuerpo que es civilización y, por consiguiente, como un microcosmos de la concepción del mundo de los griegos antiguos. Y es que -como espero demostrar- la arquitectura teatral es vista por los helenos como un cuerpo articulador, delimitado, diferenciado y separado y con entradas o salidas que comunican sus funciones interiores con las exteriores, por lo que, a pesar de su autonomía, no está aislado en sí mismo, sino que constituye una auténtica red de relaciones entre el universo teatral, la polis y el mundo.

Pero veamos detenidamente si esto es así, si la arquitectura teatral helena cumple este papel, para lo que he dividido esta investigación en dos apartados - uno dedicado a la idea del cuerpo de la sociedad y de la cultura helenas y, el otro, a la manera en la que la arquitectura teatral encarna la metáfora corporal-, con sus correspondientes subapartados.

\section{En Grecia, los cuerpos humanos están articulados con el mundo}

\subsection{El cuerpo humano está articulado y conforma una red de relaciones con la naturaleza, los dioses y la polis}

Para los griegos, la búsqueda del orden social y cultural estuvo siempre asociada a la de la unidad ${ }^{12}$, que se manifiesta tanto en el mundo natural como en el divino y en el humano. Como sugiere C. Castoriadis, en la mitología helena se distingue siempre entre tres planos, si bien es posible pasar de uno a otro: el de la naturaleza no humana -los animales y las plantas no antropomorfizados-; el de lo humano, que incluye todo lo humanizado -los animales domésticos y las plantas cultivadas-; y, finalmente, el de lo divino ${ }^{13}$. También para J. Beriain el ser humano está compuesto por él mismo, por Dios o los dioses y por el cosmos, a veces conformando una unidad de síntesis ${ }^{14}$. Esta unidad está ciertamente presente en la realidad, pero los tres se vinculan en el plano imaginario, ya que esta articulación del mundo "natural",

\footnotetext{
M. Zambrano, Persona y Democracia. La historia sacrificial, Barcelona, Anthropos, 1992, p. 76.

C. Castoriadis, Lo que hace a Grecia. 1. De Homero a Heráclito. Seminarios 1982-1983. La creación humana II, Buenos Aires, F.C.E., 2006, pp. 172-173.

14 J. Beriain, La lucha de los dioses en la modernidad. Del monoteísmo religioso al politeísmo cultural, Anthropos, Barcelona, 2000, pp. 106-108 y 131.
} 
del "sobrenatural" -más comúnmente "extrasocial"- y del "mundo humano" propiamente dicho es la que produce las instituciones y las significaciones imaginarias que conllevan ${ }^{15}$.

Como no podía ser de otra manera, el cuerpo también traduce, en sí mismo, la unidad y el orden de los tres mundos divino, natural y humano. Al respecto, no es gratuito que, según los helenos, el cuerpo humano posea algo de sagrado, puesto que, a través de su belleza, se trasluce la cháris -la gracia-, una especie de divinidad que es valorada como algo opuesto a la dimensión monstruosa y caótica y como un elemento civilizador que define el ideal de sencillez y de elegancia. Pero, a la vez, el cuerpo humano es phýsis porque sigue el ritmo de los días, de las estaciones y de los años y porque está unido al tiempo de la vida que surge, que crece y que desaparece ${ }^{16}$, sin olvidar que el cuerpo mortal pertenece a la naturaleza, que a ella debe retornar y que en ella debe abismarse. Por eso, el ser humano y su cuerpo son -como los animales y las plantas- congénitamente imperfectos y pasajeros, ya que tienen que pasar por fases de crecimiento que, finalmente, los conducen a la muerte ${ }^{17}$.

El cuerpo articulador de lo humano, de lo divino y de lo natural se evidencia en Grecia, entre otros aspectos, en el pensamiento griego cosmológico, médico, antropológico, gnoseológico y filosófico, en la arquitectura y en el urbanismo, en la mitología y en la cultura popular.

1. El pensamiento cosmológico, médico, antropológico y gnoseológico ha considerado el cuerpo como un microcosmos del cosmos, es decir, como algo que correlaciona el organismo humano y el mundo celeste. Quizás, esto constituya una herencia de las ideas caldeo-babilonias acerca del influjo de los astros en el acontecer humano, pero lo cierto es que, en Grecia, la astrología ya se encuentra completamente desarrollada en el siglo IV a.C. como resultado de un proceso que se inicia, al menos, en el pensamiento mágico y, con posterioridad, en los presocráticos. Tres son las ideas fundamentales pertenecientes a esta área de conocimiento: la concepción del ser humano como un universo en pequeño (Demócrito), es decir, la reproducción en aquel de la estructura de éste; la existencia de la simpatía universal (el Corpus Hippocraticum, los presocráticos, los estoicos y los neoplatónicos); y la presencia de la armonía en el cuerpo, en la música y en el cosmos -los pitagóricos- $-^{18}$.

De la etapa primitiva mágica proceden los tres grandes principios: "lo semejante por lo semejante" (fase primitiva animista), "la repelencia de los contrarios" y "la mutua compenetración de las partes con el todo y del todo en las partes" ${ }^{\prime 19}$. Pero estos principios van a ser, poco a poco, formulados y aprovechados científicamente por los filósofos helenos. La idea de la simpatía universal en relación con la concepción del universo como un organismo -hilozoísmo- se sugiere ya en presocráticos como Tales, Anaximandro y Anaxímenes y en los pitagóricos, que mantienen que existe una afinidad mutua entre todas las cosas de la naturaleza. Los estoicos, por su parte,

C. Castoriadis, El mundo fragmentado, La Plata (Argentina), Caronte, 2008, p. 89.

16 S. N. Eisenstad, "The Axial Age Brenkithroughhstheir Characteristics and Origins", en The Origins and Diversity of Axial Age Civilization, New York, State University, 1986, pp. 1-25; P. Laín Entralgo, La curación por la palabra en la antigüedad clásica, Barcelona, Anthropos, 2005, p. 18; P. Hadot, El velo de Isis. Ensayo sobre la historia de la idea de la Naturaleza, Barcelona, Alpha Decay, 2015, p. 40.

17 J-P. Vernant, El individuo, la muerte y el amor en la Antigua Grecia, Barcelona, Paidós, 2001, pp. 20-26.

18 I. Muñoz Valle, "El principio de la simpatía universal y la correlación entre el macrocosmo y el microcosmo en la Antigua Grecia", en Revista di Studi Classici, n 23, pp. 210-220, 1975, aquí pp. 213-220.

19 Ibidem, pp. 210 ss. 
se hacen eco de esta idea y trasladan el principio de la simpatía universal -sympátheia pánton- del organismo humano - del cuerpo- al universo. Así pues, el cosmos entero, que es un ser racional e inteligente y un organismo vivo, posee un principio que explica la simpatía de todas sus partes, en la medida en que se encuentra en todas y en cada una de ellas. $\mathrm{Y}$, al igual que en el individuo el espíritu se convierte en ese principio integrador, en el universo el pneûma, aithér o noûs adopta ese papel.

Los neoplatónicos y los médicos hipocráticos todavía llegan más lejos en el camino de la asimilación de los cuerpos humanos con el cosmos, dando lugar a una segunda analogía entre el macrocosmos y el microcosmos: el principio universal de la vida actúa en las criaturas terrestres ${ }^{20}$. Es decir, que si primero la sociedad humana ha sido el modelo sobre el que el griego crea el orden del universo, posteriormente éste se transforma en el paradigma de la sociedad ${ }^{21}$. Esta última idea, que es de origen iranio, explica que el organismo humano reproduzca en sí mismo el cosmos, identificando el modo en el que sus perturbaciones se sienten también en el cuerpo o en la psique humana. Desde esta perspectiva, Hipócrates relaciona la cabeza con el cielo, el mar con el vientre, la tierra con la carne y los ríos con la sangre ${ }^{22}$.

Epicuro vincula al cuerpo más con la tierra que con el cosmos, pues está sumido en plena naturaleza, es más, es en sí mismo naturaleza. En efecto, para este filósofo, el cuerpo se ubica en una posición central tanto dentro del orden terrestre, del más acá que es el que realmente le interesa, como de la existencia humana, ya que constituye el centro inicial del dêmos y está sometido al dolor y a la muerte, sin que esto constituya un obstáculo para que esté, al mismo tiempo, lleno de posibilidades y para que sea objeto de placer. Además, Epicuro democratiza el cuerpo y el placer, al que vincula, además, a la preeminencia que otorga a los sentidos en el conocimiento. Desde esta perspectiva, su cultura ya no forma parte de la del logos sino de la de los cuerpos, pues es en ellos donde radica el primero y esencial nivel de todo saber. Por tanto, lo que hace Epicuro es desvelar la original relación corporal y sensible con el mundo que había ocultado una sociedad basada, fundamentalmente, en el habla y en la que el lenguaje había adquirido una extraordinaria importancia ${ }^{23}$.

2. El cuerpo griego se concilia, aunque con límites, con la arquitectura y con el conjunto de la polis. Esto quiere decir que los helenos establecen una analogía directa entre cuerpo y ciudad, ya que o bien observan al cuerpo desnudo como si fuera un edificio cuyas partes muestran con claridad las líneas fronterizas ${ }^{24}, \mathrm{o}$, por el contrario, consideran que la forma urbana está basada en una concepción fisiológica del cuerpo ${ }^{25}$. Pues bien, sea este último asimilado a la arquitectura o ésta a aquél, lo cierto es que Atenas - como glorifica Pericles- armoniza "la carne" -el cuerpo humano- y la "piedra" -la arquitectura-, que el espacio -en el conjunto de la arquitectura

\footnotetext{
Ibidem, p. 213.

R. Mondolfo, En los origenes de la filosofía de la cultura, Buenos Aires, Librería Hachette, 1960, pp. 19 ss.

I. Muñoz Valle, op. cit., pp. 213-214.

E. Lledó Íñ́go, El epicureísmo, Madrid, Taurus, 2011, pp. 31-133; C. García Gual, E. Lledó, P. Hadot, Filosofía para la felicidad. Epicuro, trad. de C. García Gual, Madrid, Errata Naturae, 2013, p. 20.

24 A. Blanco Freijeiro, Arte griego, Madrid, C.S.I.C., 1990, p. 144.

25 R. Sennet, Carne y piedra. El cuerpo y la ciudad en la civilización occidental, Madrid, Alianza, 1997, pp. 35-84.
} 
helena- es considerado un volumen escultórico ${ }^{26}$, "una escultura abstracta" ${ }^{27}$ y que, por tanto -como cree Aristóteles-, es indisociable de la noción de cuerpo.

Esto es verdad particularmente para los templos, que se distinguen por ser la "metafisicización de la forma, la encarnación de lo divino en la forma"28. Y es que, si el entorno natural ya prefiguraba a la deidad que lo habitaba, cuando se le construye en ese lugar sagrado un templo y en el momento en el que se aloja la imagen divina en su interior, entonces el propio edificio personifica esculturalmente el carácter del dios y de su presencia ${ }^{29}$, su "cuerpo" podría decirse. Pero es posible que sea el de los humanos el que previamente ha determinado esta asociación, puesto que

la postura y la actitud del orante son sin duda más antiguos que sus palabras y expresión originaria del sentimiento que despierta la presencia divina. Lo que más tarde plasmó en piedra en honor del dios, fue en su día él mismo que, con los brazos alzados hacia el cielo, se elevaba como una columna, de pie o hincado de rodillas $^{30}$.

En consecuencia, este ser humano orante se convierte él mismo en monumento vivo del ser divino, es decir, que, con su propio cuerpo, creó una imagen de un dios.

En todo caso, que la arquitectura del templo constituya una analogía del cuerpo humano es un hecho que ya fue percibido por Vitruvio, el arquitecto romano del s. I., quien es posible que siguiera, en su sistema de proporciones y en su symmetria de los órdenes arquitectónicos, un canon escultórico ${ }^{31}$ y que fuera "uno de los últimos mecánicos griegos importantes" ${ }^{32}$. En todo caso, en Los Diez Libros de Arquitectura (traducción de Diego Ortiz y Sanz), en el Libro III, Capítulo I, De la Composicion y simetria de los Templos ${ }^{33}$, se ocupa concretamente de la relación que el templo debe tener con el cuerpo humano:

Ni puede ningun edificio estar bien compuesto sin la simetría y proporcion, como lo es un cuerpo humano bien formado... Así mismo el centro natural del cuerpo humano es el ombligo; pues tendido el hombre supinamente, y abiertos brazos y piernas, si se pone un pie del compas en el ombligo, y se forma un círculo con el otro, tocará los extremos de pies y manos. Lo mismo que en un círculo sucederá en un quadrado; porque si se mide de las plantas á la coronilla, y se pasa la medida transversalmente á los brazos tendidos, se hallará ser la altura igual á la anchura, resultando un quadrado perfecto.

Por tanto, el ser humano bien formado que describe Vitruvio posee proporciones armoniosas, ya que indica que su altura -4 codos- es igual a la amplitud de sus bra-

26 S. Giedion, La Arquitectura como transición (Las tres edades del Espacio en la Arquitectura), Barcelona, Gustavo Gili, 1975.

27 D. J. Boorstin., Los creadores, Barcelona, Crítica, 2008, p. 91.

28 A. Weber, Historia de la cultura, México, F.C.E., 1969, p. 95.

29 V. Scully, The Earth, The Temple and The Gods. Greek Sacred Architecture, Westford, Massachusetts, New Haven and London, Yale University Press, 1979, p. 2.

30 W. J. Otto., Dioniso, Mito y Culto, Madrid, Siruela, 1997, pp. 22-24.

D. J. Boorstin, op. cit., p. 167.

B. Gille, La cultura Técnica en Grecia, Barcelona, Juan Granica, 1985, pp. 57, 173 y 177.

Vitruvio, Los Diez Libros de Arquitectura, ed. de José Ortiz y Sanz, Madrid, Akal, 1992. 
zos extendidos por encima de la cabeza -4 codos-. De ahí que estas medidas iguales generen un cuadrado perfecto que abarca todo el cuerpo, en tanto que las manos y los pies desplazados tocan un círculo centrado en el ombligo ${ }^{34}$.

Continúa Vitruvio -en el capítulo I del Libro III aludido ${ }^{35}$ - diciendo que

Luego si la naturaleza compuso el cuerpo del hombre de manera que sus miembros tengan proporcion y correspondencia con todo él, no sin causa los antiguos establecieron tambien en la construccion de los edificios una exacta conmesuracion de cada una de sus partes con el todo. Establecido este buen orden en todas las obras, le observaron principalmente en los Templos de los Dioses, donde suelen permanecer eternamente los aciertos y errores de los artífices.

Según Ortiz y Sanz, esto es así "porque siendo edificios públicos, y dedicados á la Religion, se fabricaban para eterna duracion y permanencia...”. Así pues, las proporciones de los edificios se presentan mediante números y el diagrama del círculo-cuadrado, figuras que los pitagóricos-platónicos -a los que Vitruvio admiraconsideran perfectas.

Esta relación del cuerpo humano con el círculo y el cuadrado se asienta en la idea arquetípica de la "cuadratura del círculo", que fascina a los griegos ${ }^{36}$ (Aristófanes, las Aves, vv 1002-3; -especialmente a Homero, a los pitagóricos, a los filósofos jónicos, a Platón, a Euclides, a Apolo y Dioniso y a los mitos de Hestia y de Hermes-, en la medida en que esas formas se consideran perfectas e incluso sagradas y en tanto que, mientras que el círculo representa a las órbitas celestiales, la segunda figura geométrica encarna la "cuadrada" solidez de la tierra. Por tanto, combinados los dos en el cuerpo humano sugieren que éste fusiona, en sí mismo, las diversidades del cielo y de la tierra ${ }^{37} \mathrm{y}$, en suma, expresan el deseo del individuo de fundirse en el todo, de reintegrarse en el orden cósmico general ${ }^{38}$.

También en el resto de edificios (el gimnasio, la stoá y la arquitectura teatral -como se verá más adelante-) se muestra, de un modo especial, la influencia del cuerpo y cómo es conectado con el carácter cívico. En el gimnasio, los jóvenes aprenden el vínculo erótico existente entre ciudadano y ciudadano y entre éste y la ciudad y, por tanto, allí conocen que su cuerpo le pertenece a esta última, que forma parte de esa colectividad llamada polis. Por su parte, la stoá también recibe el influjo del cuerpo humano, ya que está formada por dos naves, una larga en la que su parte de atrás está cerrada y otra frontal abierta al agorá mediante una columnata. Mientras en el lado cerrado de la nave los ciudadanos se congregan, hablan, chismorrean, hacen negocios, compran o comen, en la parte abierta todo el mundo puede observar a los ciudadanos. Del mismo modo, el Partenón se ve desde todas las partes de la ciudad, tanto desde los barrios más antiguos como desde los más recientes. Además, en su friso -y en contraste con los de Delfos donde se marcan las distancias entre las divinidades y los hombres- aparecen cuerpos ideales,

\footnotetext{
34 G. Doczi, El poder de los límites. Proporciones armónicas en la naturaleza, el arte y la arquitectura, Buenos Aires, Troquel, 2004, p. 93. S. Skinner, Geometría sagrada, Madrid, Gaia, 2007, pp. 128-129.

Vitruvio, op. cit..

36 E. Bernárdez, "Homeomorfismo de texto y oración”, en Lengua: discurso, texto. I Simposio Internacional de análisis del discurso, coord. J. J. de Bustos Tovar, vol. 1, Madrid, 2000, p. 209.

G, Doczi, op. cit,. p. 93.

38 J-P. Vernant, op. cit., pp. 215 y 219.
} 
jóvenes, desnudos y semejantes a los dioses que simbolizan el poder humano y su deseo de fundirse con ellos.

3. La unidad existente entre los dioses y los humanos, en ocasiones, se patentiza también en el propio cuerpo humano. Ante todo porque éste es imaginado, por ejemplo en la mitología, como unido, esto es, al tiempo masculino y femenino. Así, ciertos personajes o héroes revisten caracteres bisexuales, como sucede con las Amazonas -mujeres guerreras con atributos masculinos- o con Heracles - un hombre fuerte, viril, que es obligado a vestirse con ropas de mujer- ${ }^{39}$. Igualmente, Platón (en el Banquete, $189 \mathrm{~d}-\mathrm{e})^{40}$ habla de unos seres, con simultáneas características masculinas y femeninas, que tratan de invadir el Monte Olimpo donde viven los dioses, por lo que Zeus, intentando obstaculizarlo, les envía un rayo que los divide en dos, lo que da lugar a la necesidad de buscar nuestra otra mitad.

También el cuerpo popular -el grotesco-, el que está presente en los rituales, en los festejos o en los personajes de la comedia de Aristófanes, representa otro modo de articulación, en la medida en que no está ni separado ni aislado del resto del mundo sino enredado con él y confundido con los animales y las cosas, no en balde sale fuera de sí y franquea sus propios límites, de manera que difumina las fronteras y la dualidad. Por eso, el cuerpo enfatiza las partes que se abren al exterior o que penetran en él a través de orificios, protuberancias, ramificaciones y excrecencias tales como la boca abierta, los órganos genitales, los senos, los falos, las barrigas y la nariz. Además, la esencia del cuerpo grotesco es el cambio, la metamorfosis y el crecimiento, ya que siempre es incompleto e indiferente a la perfección estática y puesto que es eternamente creado y creador, lo que se manifiesta en actos como el coito, el embarazo, el alumbramiento, la agonía, la comida, la bebida y la satisfacción de las necesidades naturales. En consecuencia, muestra una edad muy cercana al nacimiento y a la muerte, a la primera infancia y a la vejez, y acentúa su proximidad al vientre y a la tumba, al seno que lo concibe y al que lo amortaja. En efecto, es un cuerpo simultáneamente agonizante-naciente o a punto de nacer que se sitúa en el umbral de la tumba y de la cuna. En su seno, pues, la individualidad está en proceso de disolución, ya que exhibe dos cuerpos en uno, resultado de la fusión de ambos, o mejor, no constituye un cuerpo único ni tampoco dos en tanto que dos pulsos laten en su interior: uno que da la vida y desaparece y otro que es concebido y arrojado al mundo. En este sentido, no extrañe que se halle siempre en estado de embarazo y alumbramiento o, por lo menos, preparado para concebir y ser fecundado con un falo o con órganos genitales exagerados ${ }^{41}$.

Todas estas peculiaridades, que pueden ser denominadas fisiológico-corporales, situacionales y relacionales y que definen a un tipo de ser humano no cerrado sino abierto al mundo-, se mantendrán vigentes desde Homero hasta Platón. Pero cabe matizar que, si Homero requiere un yo en diálogo, Platón prefiere un yo abstraído; y,

\footnotetext{
J. Libis, El mito del andrógino, Madrid, Siruela, 2001, p. 106.

40 Platón, Diálogos, vol. III (Fedón, Banquete, Fedro), introducciones, traducciones y notas de C. García Gual, M. Martínez Hernández y E. Lledó Íñigo, Madrid, Gredos, 2000.

41 V. Turner, "Variations on a Theme of Liminality", en Secular Ritual, S. F. Moore y \& B. G. Myerhoff (eds.), Assen/Ámsterdam, Van Gorcum, pp. 36-52, 1977, aquí p. 38. M. Bajtin, La cultura popular en la Edad Media y en el Renacimiento. El contexto de François Rabelais, Madrid, Alianza, 2003, pp. 25-26. E. Alemán Salcedo, Homo Transiens, liminaridad y límites en disputa. Claves interpretativas para una sociología de lo liminar, Tesis Doctoral, Universidad Pública de Navarra, Pamplona, 2011, pp. 116, 346-348.
} 
si la épica homérica no tiene en cuenta las distinciones entre el alma y el cuerpo ${ }^{42}$ y la separación o abstracción del ser humano con respecto al mundo, al medio en el que vive, Platón (Fedón, 64c, 69e-84b) ${ }^{43}$ piensa que la psyché -el alma-tiene privilegio y que es una cosa inmortal diferente y superior al cuerpo. Ello sin olvidar que constituye la sede de la vida mental e intelectual del hombre, su verdadero yo, aquello que constituye su auténtico ser. En suma, Platón define un ser humano que se ha cerrado con respecto al mundo y que ha roto la vinculación con él ${ }^{44}$.

\subsection{El cuerpo masculino, desnudo, y, el femenino, velado}

Ahora bien, la fractura del cuerpo con el mundo o con otros cuerpos no la encontramos solo en Platón, pues también está presente en la propia ciudad y, de un modo muy intenso, en la separación de géneros. En efecto, la aparente armonía entre la carne y la piedra que se ha descrito antes no es, sin embargo, total, ya que exhibe dos llamativos límites: la presencia del dolor y la división de los cuerpos ${ }^{45}$. Así, el dolor que sufre el cuerpo se convierte en un obstáculo para alcanzar la unidad entre éste y la ciudad. Al respecto, Tucídides (Libro II, 48-54) ${ }^{46}$, cuando describe la peste que asola a Atenas y el padecimiento que genera, cuenta cómo en los momentos cruciales en los que los atenienses padecen no hallan alivio en las piedras de la ciudad, por más monumentales y hermosas que éstas sean. En estas circunstancias, la desnudez tampoco encuentra ningún fármaco contra el tormento, lo que evidencia que la armonía entre la carne y la piedra es ideal y no real. Esto es así si se tiene en cuenta que este triunfo del dolor frente a la armonía tiene que ver con que el plano ideal no es carnal, sino mental; y con el hecho de que la carne, por mucho sentido colectivo que exista en la ciudad, en el fondo, es individual y mortal y está adherida a un cuerpo singular, mientras que la piedra está unida a otras piedras por una argamasa y busca expresar la inmortalidad.

El segundo límite de la armonía entre la carne y la piedra lo constituye, en Atenas, la separación de los cuerpos en relación al poder de la palabra y al género. Y es que los ciudadanos varones no parecen alcanzar la plena armonía e igualdad de la voz en los distintos espacios urbanos. Si en el agorá existen numerosas actividades diferenciadas que impiden que una voz se convierta en dominante, por el contrario, en la Pnyx el pueblo se torna vulnerable, ya que no puede desplazarse y queda rehén de las voces individuales de los oradores que, en ese momento, hablan.

También las mujeres son separadas del espacio común porque están encerradas en el gineceo, en el hogar, al encargarse de la economía doméstica. Para ello, necesitan aprender algunas nociones básicas de aritmética y de alfabetización, como muestra la Figura de terracota de niña sentada escribiendo, que está pulsando el estilo sobre un tablero plegable, del siglo IV a.C., procedente de Enkomi, Citio o Salamina (Chipre), y que se halla en el British Museum. Pero estas nociones que reciben las mujeres no les permiten convertirse en ciudadanas, ni abandonar el margen

\footnotetext{
J-P. Vernant, 2001, p. 17.

Platón, op. cit.

J. C. Rodríguez Delgado, El desarme de la cultura. Una lectura de la Ilíada, Madrid, Katz, 2010, pp. 78-130.

R. Sennet, op. cit., pp. 28-37.

Tucidides, Historia de la Guerra del Peloponeso. Libros I-II, Introducción general, traducción y notas de J. J. Torres Esbarranch, Madrid, Biblioteca Clásica Gredos, 2000.
} 
de la comunidad en la que son ubicadas. Así se explica que, en el club de hombres que constituye la ciudad, las mujeres sean consideradas unas eternas menores, que encarnen la inversión de valores cívicos -son óros, montaña ${ }^{47}$, o fiestas dionisíacas $^{48}$ - y que simbolicen aquello que pone en peligro el orden establecido: lo salvaje, lo inmaduro, lo húmedo, lo bárbaro, lo sometido y lo tiranizado. Aristóteles emplea, por primera vez, el concepto de "ciudadana", pero sin que posea ningún rol político, lo que demuestra que, en toda la historia helena, las mujeres no alcanzan la igualdad, como tampoco lo hacen sus cuerpos en relación con el de los hombres. Sin embargo, representan la mitad de la ciudad ${ }^{49}$ y de ahí que ocupen un importante lugar en el imaginario griego, que construye una imagen de las mismas inferior, pero indispensable. A ello ayuda el que su participación pública se efectúe a través de los sacerdocios y de los rituales ciudadanos, pero sobre todo cumpliendo adecuadamente sus esenciales papeles de género: la reproducción -Deméter, Ártemis y Dioniso- y el trabajo doméstico -Atenea- ${ }^{50}$.

Este papel secundario de lo femenino se aprecia con transparencia en las fiestas de Adonis, celebraciones que transforman -al igual que las Tesmoforias- un antiguo rito agrícola en una experiencia urbana y que celebran el deseo sexual de las mujeres en el tejado de las casas. Concretamente, el viejo mito asocia la fecundación de los campos con la muerte del placer, porque cuenta que un Adonis agonizante derrama su sangre sobre la tierra, expresándose así que ésta se alimenta del sufrimiento humano. En contraste, en el ritual de la ciudad, se exhibe el agostamiento de los cultivos y el marchitamiento de sus plantas, lo que permite el retorno del cuerpo sensual a la vida, del cuerpo de las mujeres que, ciertamente, parecen recuperar su capacidad de hablar y de manifestar sus deseos. Pero, no nos engañemos, el retorno es temporal y se produce a oscuras, casi de tapadillo y no en las plazas o en las calles públicas. Así, frente a los espacios urbanos dominantes -el agorá, el gimnasio, la acropólis y la colina de la Pnyx-, que son lugares de participación ciudadana bajo la luz diurna, las mujeres se reúnen en las fiestas de Adonis en los techos de las casas, por las noches y con escasas y no demasiado potentes luminarias encendidas. No extrañe que no sea posible una visión clara de las figuras femeninas, estén éstas sentadas o caminando por la calle, $\mathrm{y}$, por supuesto, tampoco permiten su participación en política o que sean consideradas del cuerpo ciudadano.

Por otra parte, la división de géneros se aprecia también a través de la reglamentación del desnudo y del vestido, asociados, respectivamente, con el hombre y la mujer y, correlativamente, con lo civilizado y lo bárbaro. En otras sociedades como la mesopotámica, el desnudo representa la ausencia de estatus o la cercanía con la divinidad - por ejemplo, en los sirvientes desnudos que contrastan con los sacerdotes engalanados y que portan ofrendas a los dioses en el Vaso de Uruk ${ }^{5 l}-$ o el contacto con Dios y la Naturaleza-Adán y Eva desnudos en el Paraíso ${ }^{52}$-. En Grecia, el desnudo se puede asociar con lo originario, con los cuerpos descubiertos de los

47 R. Buxton, El imaginario griego. Los contextos de la mitología, Madrid, Cambridge University Press, 2000, pp. $88-101$.

48 A. Escohotado, "Dionisos y la orgía", REIS, 34/86, 1986, p. 199.

49 C. Mossé, La mujer en la Grecia clásica, Madrid, Nerea, 2001, pp. 43, 158 y 161.

$50 \quad \mathrm{M}^{\mathrm{a}}$. D. Mirón Pérez, "El gobierno de la casa en Atenas Clásica: género y poder en el Oikos", en Stud. Hist., $H^{a}$. Antig., 18, Universidad de Salamanca, pp. 103-117, 2000b, aquí p. 106.

51 H. Frankfort, Arte y arquitectura del Oriente Antiguo, Madrid, Cátedra, 2000, p. 27.

52 N. Frye, Poderosas Palabras, Barcelona, Muchnik, 1996, pp. 250 ss. 
animales, con ese tiempo en el que los hombres no conocen el arte de tejer y deben cubrirse con pieles o ir sin vestir ${ }^{53}$, es decir, que constituye -sobre todo, en el arcaísmo- un signo de primitivismo y brutalidad ${ }^{54}$. Pero, normalmente, el sentido griego dominante conecta el desnudo con la cultura y la civilización. Y es que -a diferencia de Mesopotamia- la desnudez no simboliza jerarquización sino la igualdad de los cuerpos y su ligamento a la democracia, y no evidencia el contacto con la naturaleza sino con el trabajo cultural del cuerpo.

Se entiende, así, que el desnudo limpio y puro, que domina en el arte desde el Período Geométrico, constituya un atributo viril que permite al guerrero enseñar gran parte de su cuerpo como si éste fuera un arma. Es más, es presentado de tal manera que parece también el resultado de un ejercicio regular, lo que le otorga una dimensión eminentemente cultural. La desnudez exhibe con orgullo la musculatura constitutiva del físico y la manera en que ésta encarna no un simple fruto de la naturaleza sino un artificio similar al que hacen las mujeres con sus manos. Mientras ellas se ocultan tras obstinados velos, a veces sutiles y eróticos, $\mathrm{y}$, cuando en escasas ocasiones aparecen desnudas, es para representar determinados actos violentos y no normativos como la violación. Así pues, la indumentaria es considerada una segunda piel del cuerpo femenino, en el sentido de que el vestido de las hermanas y de las esposas de los guerreros las define y las distingue en sociedad. Las atenienses, por ejemplo, se colocan encima de la túnica larga -el péplos o el chitón-, ceñida a su figura, el chal o velo, que es un signo de virtudes femeninas tales como el pudor, el recato y la modestia, aunque también de seducción. Y, lo que es más importante, los vestidos de las mujeres se vinculan con las principales actividades que desempeñan en el gineceo y que suponen su principal aportación a la vida civilizada de la polis. Me refiero a las labores que les permiten integrar el producto de su trabajo como parte de su ser, esto es, el telar y el cuidado de los tejidos y de su propia apariencia, pero también de su vestuario, ya que -junto con las paredes del hogar- las protege y, simultáneamente, las aísla del mundo exterior.

En consecuencia, el poder corporal no genera la unidad cívica porque la política no consigue recrear una igualdad, una armonía y una integridad mutua que solo se mantienen en un nivel ideal. Es más, el cuerpo del ciudadano, "desnudo" e indefenso ante el poder que se expresa con la voz, se transforma en un cuerpo roto -el de los individuos-y pasivo que no se armoniza plenamente con el del conjunto de la ciudad.

\subsection{El cuerpo y los sentidos}

Probablemente, esta pasividad de los cuerpos esté relacionada con el papel prioritario que los griegos le otorgan a la visión. Como dice Aristóteles, en la Metafísica (A, 1980 a 21) $)^{55}$, las sensaciones visuales son las más amadas por los hombres, lo que quiere decir que "en el ser del hombre se da esencialmente el cuidado por el ver",

$53 \quad \mathrm{M}^{\mathrm{a}}$. C. Cardete Del Olmo, Paisajes mentales y religiosos. La frontera suroeste arcadia en épocas arcaica y clásica, Oxford, BAR International Series 1365, 2005a, p. 178.

54 C. Delgado Linacero, "La Gigantomaquia, símbolo socio-político en la concepción de la polis griega", Espacio, Tiempo y Forma, Serie II, Historia Antigua, t. 12, 1999, p. 110.

55 Aristóteles, Metafísica, introducción, traducción y notas de T. Calvo Martínez, Madrid, Gredos, 2000. 
que el ver descubre el ser ${ }^{56}$. Es muy significativa, al respecto, la función del theōrós, el espectador que, en su origen, está ligado a la contemplación del universo y que, posteriormente, es enviado a consultar un oráculo o a las ciudades griegas como observador de las fiestas o de los juegos que allí se celebran, por lo que reúne en su persona dos rasgos vitales de la religiosidad helena: la festividad en sí misma y el punto de vista del espectador. No extrañe, pues, que el theōrós contemple las cosas lúdicamente y a distancia -observa lo que sucede en una ciudad diferente a la suya-, pero a una distancia no insalvable por cuanto que toda forma de religiosidad griega es un asunto común que le atañe y que le pertenece ${ }^{57}$.

Por otra parte, aunque los oídos cumplen en Grecia una función de control social y la experiencia auditiva es muy importante para la supervivencia de la memoria y para la transmisión de la cultura -por ejemplo, en la Ilíada (Canto XIV, 388-401) ${ }^{58}$ las crisis más importantes son marcadas a través de potentes sonidos-, "los hombres desconfían más de sus oídos que de sus ojos" (Heródoto, Historia Libro I, 8, $2)^{59}$, es decir, que priorizan más la visión como el medio básico del conocimiento y de la emoción. Se explica, así, que los griegos sean "los espectadores" por antonomasia $^{60}$ y que la visión -como sucede en el mito del príncipe Argos, cuyo cuerpo se encontraba cubierto de ojos- se asocie con la luz, el conocimiento y la vida, mientras que la ceguera lo hace con el sueño y con la muerte ${ }^{61}$. Además, el ojo constituye el lugar del origen del deseo y, en la épica y en la tragedia, es el órgano utilizado para expresar las emociones más fuertes y complejas. En este sentido, a Homero y a Heródoto les fascinan los detalles visuales que presenta la superficie del mundo, es decir, que sienten pasión por la claridad visual del universo fenoménico. No sorprenda, pues, que en ellos la concepción del guerrero sea visual y que éste sea descrito con llamativos elementos decorativos como el penacho, las plumas o el brillante metal.

También para los físicos jonios de los siglos VI y V a.C. el mundo en sí deviene un espectáculo, pero éste está ordenado mediante la razón $\mathrm{y}$, en consecuencia, se presenta como un todo que es posible percibir visualmente y entender en el intelecto mediante las relaciones abstractas basadas en la geometría. De este modo, los presocráticos pueden conformar un "espectáculo" — theoria - más apropiado para la mente que para el sentido de la vista y reemplazar, con este proceso, el mýthos por el logos, así como la imaginería antropomórfica por una theoria más abstracta. No por casualidad, en el origen de esta especulación filosófica, se halla la teoría, concebida como una delegación o sagrada embajada en forma de juegos, fiestas o cultos panhelénicos. Además, en los cultos mistéricos de Eleusis, el iniciado es denominado epóptes — "el que contempla"_-, mientras que, en el resto de celebraciones en honor de los dioses, el theōrós es el espectador de los juegos y, consecutivamente, el que comprende el sentido de la fiesta. Entre estas actividades espectaculares destaca, posiblemente, la guerra por encima de todas por su grandiosidad y por la repercusión

\footnotetext{
M. Heidegger, Ser y tiempo, Madrid, Trotta, 2003, pp. 193-194.

Parménides, Poema, ed. de J. Llansó, Madrid, Akal, 2007, p. 65.

Homero, Ilíada, Introducción general, traducción y notas de E. Crespo Güemes, Madrid, Gredos, 2000.

Heródoto, Historia. Libros I-II, Introducción general, traducción y notas de C. Schrader, Madrid, Gredos, 2000.

Ch. Segal, "El espectador y el oyente", en El hombre griego, ed. de J-P. Vernant, Madrid, Alianza, 1993, pp. 231-225.

${ }_{61}$ R. Gubern, La mirada opulenta. Exploración de la iconosfera contemporánea, Barcelona, Gustavo Gili, 1992, p. 2 .
} 
en la polis, especialmente en sus momentos inicial y final. En todo caso, los espectáculos más fastuosos y más destacados no son los de la naturaleza ni los individuales, sino las reuniones comunitarias que desarrollan rituales religiosos, festivales, actividades deportivas, musicales y teatrales.

\section{La arquitectura teatral griega constituye una analogía del cuerpo humano político}

\subsection{Edificio teatral representa un cuerpo articulado, cósmico, masculino y femenino que ve, oye y habla}

1. Ante todo, en Grecia la arquitectura teatral griega está articulada del mismo modo que el cuerpo. $\mathrm{Si}$-según el filósofo G. Gadamer ${ }^{62}$ - la arquitectura remite siempre más allá de sí misma en una doble dirección en tanto que está condicionada tanto por el objetivo al que debe servir como por el lugar que ha de ocupar en el conjunto de un determinado contexto espacial, de esto se sigue que los teatros helenos suponen sólo una parte de lo que se podría llamar "la arquitectura" de un lugar dado y que ésta no la constituye un único edificio sino un complejo espacio-tiempo cultural que condensa la interrelación entre el paisaje y la construcción y entre ésta y los demás edificios $^{63}$. Y todo ello, en el edificio teatral heleno, se concreta en el encuentro o contraste entre sus formas interiores y las exteriores de uso y de espacio ${ }^{64}$, entendiendo por funciones interiores las que están determinadas por los objetivos que debe cumplir, mientras que las exteriores lo están por el paisaje en el que está enclavado y con el que se vincula, es decir, con la naturaleza y con la ciudad.

En este sentido, conviene tener presente que el théatron no puede comprenderse sin explicar el porqué y el cómo se interrelaciona con el paisaje natural colindante (divinizado - las montañas, las praderas y el mar-y domesticado -los campos de cultivo-, esto es, lleno de dioses y de humanos) conscientemente escogido para buscar armonía ${ }^{65}$. Es más, este paisaje ejerce una profunda influencia en el diseño de los teatros ${ }^{66}$, de manera que esta conexión teatro-naturaleza esconde un rico significado. Por este motivo, el espectáculo natural con el que confronta a los griegos no solo debió calar por sus cualidades estéticas o visuales sino también por un hondo contenido existencial humano ${ }^{67}$.

Pero al mismo tiempo que la arquitectura teatral helena se ubica en la naturaleza, es propio también de ella situarse a las afueras de la polis -con la excepción del teatro del Pireo y tal vez también del de Larisa-, de tal modo que las escenas con-

H-G. Gadamer, Verdad y Método, Salamanca, Sígueme, 1977, pp. 189 ss.

63 V. Scully, The Earth, The Temple and The Gods. Greek Sacred Architecture, Westford, Massachusetts, New Haven and London, Yale University Press, 1979, pp. 2-3.

64 R. Venturi, Complejidad y contradicción en la arquitectura, Barcelona, Gustavo Gili, 1992, p. 139.

65 N. Haddad, M. Jamhawi y T. S. Akasheh, "Relations between Ancient Teatres, Landsccape and Society", en Second International Conference on Archaeology and conservation, T. S. Akasheh editor, Consejería de Cultura de la Junta de Andalucía, Fundación el Legado Andalusí, Granada, 2007, p. 245.

66 Haddad et al, op. cit., p. 243.

67 Ch. Norberg-Schulz, Genius Loci. Paesaggio Ambiente Architettura, Milano, Electa, 1998, p. 5. 
templadas por los espectadores desde la cavea debían quedar muy lejos del "cálido" perímetro urbano ${ }^{68}$. Es probable que esto esté relacionado con la similitud entre el arte y el rito, puesto que -al igual que sucede con el theōrós, al que aludiré más tarde-, se permite a los espectadores que salgan de su ciudad para observar, desde esa perspectiva distante, lo que les es propio. Además, la arquitectura teatral se dispone al margen del resto de la vida con la finalidad de que sea capaz de ejercer cierto poder sobre ella ${ }^{69}$. En este sentido, la edificación del théatron en la periferia de la polis busca mantener el sentido ritual y religioso del drama, ya que éste constituye para el ser humano un alto anual en su vida que lo conduce al exterior de la ciudad para reflexionar sobre las relaciones con los dioses, sobre el significado trascendente de la propia responsabilidad y acerca de la ley que rige la vida del ciudadano y de la sociedad $^{70}$. Al respecto, conviene recordar que esta situación en la periferia urbana, donde por cierto también se dispone normalmente la necrópolis ${ }^{71}$, vincula al edificio con la muerte y en particular con el deseo de acercarse momentáneamente a los espíritus de los fallecidos. Así pues, la disposición del edificio teatral al exterior de la polis se halla en relación con el alejamiento temporal y espacial de la vida diaria -no se olvide que sólo seis días al año se dedican a las representaciones dramáticas en Grecia en época de Pericles ${ }^{72}$, lo que refuerza todavía más este distanciamiento de lo cotidiano-.

Por tanto, puede concebirse el teatro heleno como un monumental edificio imbricado, formal y estructuralmente, en el paisaje urbano y natural y convertido, así, en símbolo de la naturaleza, de la divinidad y del ser humano, o lo que es lo mismo, en un microcosmos de la concepción del mundo helena.

Por otra parte, el edificio teatral imita al sujeto que posee un cuerpo articulador, puesto que está -como éste- delimitado, diferenciado, separado, con su interior y exterior y con entradas y salidas para su comunicación con el entorno. Además, no está encerrado en sí mismo, enclaustrado o aislado y resulta permeable a las fuerzas que lo animan, a la intrusión de potencias vitales.

A ello se refiere Vitruvio, para quien el edificio teatral representa una analogía del cuerpo humano, ya que el esquema geométrico que rige todo el plan de la arquitectura teatral está basado -al igual que en los templos- en el diagrama del círculo y del cuadrado. Pero, en la medida en que este diagrama simboliza al cuerpo humano -como dice el propio arquitecto; véase, al respecto, la imagen de la edición francesa del libro de Vitruvio ${ }^{73}$, la antropometría, o mejor la euritmia antropométrica, constituye el fundamento sobre el que se modela todo el organismo. No en balde, posibilita que sea precisamente la unidad o módulo del cuerpo humano la que guíe todas las magnitudes y la que permita que cada miembro arquitectónico derive su

\footnotetext{
E. Lledó Íñigo, El epicureísmo, Madrid, Taurus, 2011, pp. 55-56.

J. Berger, Modos de ver, Barcelona, Gustavo Gili, 1975, p. 41.

Ma . C. Bobes, Semiología de la Obra Dramática, Madrid, Taurus, 1987, p. 248.

J. L. Menéndez Varela, "La monarquía griega antes de la constitución de la Polis. Algunas consideraciones sobre el caso ateniense", en HABIS, 34, pp. 21-37, 2003a', p. 20; J. L. Menéndez Varela, Consideraciones acerca del origen y la naturaleza de la ciudad planificada en las colonias griegas de Occidente, Oxford, BAR International Series 1104, 2003b, p. 183.

72 M. A. Elvira, "La organización de los espectáculos", en El Teatro Griego, Madrid, Cuadernos Historia 16, nº. 292, 1985.

73 Vitruvio, Les dix libres d'architecture, Préface Antoine Picon, Ligugé, Poitiers, Bibliothèque de l'image, 1995, p. 55.
} 
forma, medida y lugar de una pauta merced a una ley de analogía que relaciona las partes entre sí y a éstas con el todo ${ }^{74}$. Además, la euritmia antropométrica inherente a ese diagrama desvela a un ser humano ambivalente, un cuerpo -como el grotesco- confundido con los seres y las cosas que le rodean, que difumina, por tanto, las fronteras y la dualidad y que, en consecuencia, es, al mismo tiempo, terrestre y celeste, religioso y político, racional y secular, vital y mortal, individual y colectivo y masculino y femenino.

2. Justamente la arquitectura teatral helena simboliza un cuerpo que es tanto masculino como femenino. Al estar construida al aire libre, abierta a la naturaleza, a los dioses, al cosmos y a la sociedad, semeja un cuerpo desnudo masculino, en contraste con los templos que están "vestidos" y que, por eso, pueden ser considerados femeninos. No es gratuito que los pliegues de sus columnas se asemejen a los de las indumentarias, como parece atestiguarlo el Templo de las Cariátides del Partenón con los rostros de mujeres de sus columnas.

No obstante, algo de femenino tiene también el edificio teatral, pues el analemma -muro de sostén de las parodoi y de la cavea- cierra el edificio y lo "protege", al igual que hace el atuendo con las mujeres. Pero, además, las puertas del teatro-como las de la ciudad ${ }^{75}$ - constituyen un símbolo de lo femenino. Al entrar por esas puertas, los espectadores rememoran las viejas procesiones con el falo desarrolladas en diversos cultos agrarios y, particularmente, en los de Dioniso. Como informa Semo de Delos (en Ateneo, XIV 622 $2^{\mathrm{a}}$-d=FHG IV 496), la phallophoría - un canto fálico- se dirige en procesión hasta la orchestra circular del teatro porque este emplazamiento constituye la réplica de los recintos verdes donde las fiestas se desarrollaban desde la antigüedad (Dioniso es el dios fálico desde el siglo VII a.C.). Así pues, esta procesión "penetra" triunfalmente en el recinto de una pradera-orchestra y lo hace recordando también la hierogamia entre, por ejemplo, Helios y Gaia (que, por cierto, recoge Esquilo, en el Prometeo, 90 ${ }^{76}$. Igualmente testigo de estos viejos rituales es la obra Los Acarnienses de Aristófanes (vv 240 ss) ${ }^{77}$, pues en ella se representa el kómos que está presidido por el falo ritual del culto dionisíaco y que rememora la celebración de la fertilidad sexual y natural y sus ciclos, connaturales a las fiestas agrarias de Dioniso y de Deméter, precisamente los dos dioses que convoca el comediógrafo en sus obras.

Así pues, con este ritual, se muestra en la arquitectura teatral la relación sexual entre dos cuerpos - masculino y femenino-, la fecundación, la fertilidad, pues el órchis -el testículo- entra en contacto con el símbolo físico que manifiestan las entradas, las "aperturas". Además, si la orchestra, por su forma circular, simboliza al órgano sexual femenino, la entrada del coro en ella encarna su "penetración" por el falo, por el órchis ${ }^{78}$. En este sentido, me parece conveniente recordar que, en la religiosidad de

\footnotetext{
G. A. Breyer, Teatro: el ámbito escénico, Buenos Aires, C.E. América Latina, 1968, p. 34.

V. Ivanov, "Contribución al estudio semiótico de la historia cultural de la gran ciudad", en Escritos. Revista del Centro de Ciencias del Lenguaje, número 8, enero-diciembre, pp. 107-127, 1993, p. 116.

76 Esquilo, Tragedias completas (Los Persas. Los siete contra Tebas. Las Suplicantes. Agamenón. Las Coéforas. Las Euménides. Prometeo Encadenado), Introducción y notas de C. Miralles. Versión rítmica de M. Fernández-Galiano, Barcelona, Planeta, 1993.

77 Aristófanes, Comedias. Los Acarnienses. Los Caballeros, introducción general de J. García López, traducción y notas de L. Gil Fernández, Madrid, Gredos, 2000.

78 C. Garrocho Sandoval, El lenguaje de la infectología. Las palabras y sus orígenes, México, Universidad San Luis de Potosi, 1995, p. 117.
} 
la Diosa Madre ${ }^{79}$, la vulva o matriz de la Madre Tierra o el ingreso al útero materno es asociada a las nociones espaciales de ancho, de círculo y de centro y que, posiblemente, la palabra órchis se relaciona etimológicamente con "orchestra".

Otra cuestión importante de los edificios teatrales es su dialéctica entre la verticalidad y la horizontalidad. Ante todo, porque éstos excavan su cavea en laderas de montañas, mientras que su orchestra y su edificio palcoescénico se asientan sobre una pradera que contempla una o más montañas, islas o el mar. En todo caso, la verticalidad de los edificios teatrales remite -al igual que los trazados geométricos bien delimitados, el cuadrado del diseño de la orchestra, las líneas rectas y el rectángulo del edificio palcoescénico- a los simbolismos y abstracciones masculinas ${ }^{80}$ (religiosas -de los dioses olímpicos- y políticas - de la acrópolis y del poder político-. Mientras que la horizontalidad -característica del conjunto de la arquitectura helena ${ }^{81}$, del mismo modo que el círculo de la orchestra o el semicírculo de la cavea, lo hace al femenino, ya que lo horizontal representa el arraigo con la tierra, con lo telúrico, con lo ctónico y con las divinidades de la Diosa Madre, lo que queda reforzado por la interrelación que el edificio teatral establece con el paisaje natural circundante y sus "femeninas" formas -las montañas, las cuevas y las praderas-.

Dado el equilibrio que, en general, mantienen los edificios teatrales entre la horizontalidad y la verticalidad -con la excepción de Pérgamo, donde domina esta última-, se puede decir que constituyen una analogía del cuerpo humano masculino y femenino, sin decantarse claramente por uno o por otro y mostrando más bien su bisexualidad, su carácter hermafrodita o andrógino. Al respecto, es reveladora la interpretación psicoanalítica del espacio teatral a partir de El nacimiento de la Tragedia de Nietzsche, pues, en ella, se define al coro como el "seno materno" mientras que el actor encarna el mundo apolíneo de la acción hablada y del padre primitivo ${ }^{82}$. Si se tiene en cuenta, además, que en los teatros asisten los varones pero probablemente también las mujeres ${ }^{83}$ y que, en ellos, se representan obras en las que el oîkos, la familia, el hogar, representa un factor fundamental, no parece por tanto ilógico pensar que el edificio, en sí mismo -y no solo por el edificio palcoescénico, un espacio entre bastidores, un umbral intermedio, que muestra el interior de la casa o del palacio ${ }^{84}$, y con sus caracteres formales masculinos y femeninos, remita a la bisexualidad, a la mezcla de lo masculino y femenino y, en suma, a la unidad funcional familiar de hombre y mujer, tan necesaria en una sociedad fundamentalmente agrícola y autosuficiente ${ }^{85}$.

79 M. Gimbutas, Diosas y dioses de la vieja Europa, Madrid, Ediciones Istmo, 1991, pp. 233 ss. M. Gimbutas, "La religiosidad de la Diosa en la Europa Mediterránea", en Tratado de Antropología de lo sagrado: las civilizaciones del Mediterráneo y lo Sagrado, Madrid, Trotta, 1997, p. 47; S. Husain, La Diosa. Creación, fertilidad y abundancia. Mitos y arquetipos femeninos, Colonia, Taschen, 2001, pp. 54 y 163.

80 L. Mumford, La ciudad en la historia, Buenos Aires, Ediciones Infinito, 1979, pp. 18-34; G. Agamben, "Metrópolis", The European Graduate School, Graduate and Postgraduate Studies, s.a.

81 A. Blanco Freijeiro, Arte griego, Madrid, C.S.I.C., 1990, p. 352.

82 A. Green, El complejo de Edipo en la tragedia, Barcelona, Ediciones Buenos Aires, 1982, p. 117.

83 O. Longo, "Teatri e Theatra. Spazi teatrali e luoghi politici nella città greca", Dioniso, n' 58, 1988, p. 32.

84 J. Roux, "A propos du décor dans les tragédies d'Euripide", REG, 74, pp. 25-60, 1961, p. 39.

85 R. Buxton, op. cit., p.74; R. Descat, “Aux origines de 1'oikonomia grecque”, Quaderni Urbinati di Cultura Classica, 1988, p. 106; Ma . D. Mirón Pérez, "Las mujeres, la tierra y los animales: naturaleza femenina y cultura política en Grecia antigua", Florentia Iliberritana: Revista de Estudios de la antigüedad clásica, vol. II, 2000", pp. 65-109; C. Mossé, La mujer en la Grecia clásica, Madrid, Nerea, 2001, p. 39; J. Gallego, “Agricultura familiar y paisajes rurales en la Grecia antigua", en $C I B C E, \mathrm{n}^{\circ} 11$, pp. 135-152, 2007, aquí p. 143. 
3. Por lo demás, la arquitectura teatral griega constituye una alegoría del cuerpo humano por su preocupación por el ojo que contempla, así como por la voz y el oído que habla y escucha. En este sentido, conviene recordar que Theatron significa justamente "lugar para ver" (Onians: 1996, 229) y que el asistente al espectáculo dramático recuerda al theōrós que -como se ha dicho- es enviado fuera de su ciudad para contemplar otras fiestas y juegos con un marcado carácter lúdico y religioso y a una distancia que no es insalvable. De hecho, la cavea donde se sienta está situada frente a la orchestra y el palcoescénico, a una cierta distancia, sí, pero adecuada para que se pueda ver y oír perfectamente la representación. Relacionado con ello, no es gratuito que el teatro vincule la percepción visual clara de una figura apartada con una voz que se oye más cerca de lo que parece ${ }^{86}$. Además, se ha de tener en cuenta que el edificio necesita del acompañamiento de la voz humana ${ }^{87}$, ya que justamente es la palabra la que focaliza el espacio y la que crea la escenografía. Precisamente en relación con la voz, es muy indicativo el caso de Atenas, que distingue su valor en función del lugar donde se proyecta. Así, si en el agorá, a pesar de que se desarrollan multitud de actividades distintas, no se permite la existencia de una palabra dominante; por el contrario, en el teatro existe una destacada voz individual que se transforma -mediante la retórica- en obra de arte. mientras el público permanece -en general- en silencio ${ }^{88}$.

También el oído es fundamental para el edificio teatral, hasta el punto de que una de las teorías clásicas sobre la evolución de su forma insiste en que ésta está condicionada, en gran parte, por cuestiones de tipo acústico ${ }^{89}$. En este sentido, realmente es muy importante la elección del lugar y también la atención prestada, particularmente desde el siglo IV a.C., a las condiciones acústicas del auditorio, ya que entonces se acude a algunos recursos para aumentar su resonancia ${ }^{90}$. Entre ellos, se encuentra la introducción de una pared de fondo en la cavea que refleja el sonido procedente de los actores para dirigirse hacia el público. Así, según sus propiedades acústicas, Vitruvio clasifica los teatros en cuatro tipos: disonantes, circunsonantes, resonantes y consonantes, siendo este último tipo el ideal desde la perspectiva sonora. En todos ellos, la voz fluye desde la orchestra o el edificio palcoescénico en ondas circulares hasta alcanzar los puntos más altos de las gradas y sin hallar obstáculo alguno que impida su propagación. De hecho, la comprensión acústica del teatro griego es mejor que la romana $^{91}$, lo que consigue mediante la medida y oportuna distancia existente entre los actores y la audiencia. Por ejemplo, en Megalópolis -de manera similar a lo que sucede en el teatro de Dioniso en Atenas-, ésta es de $30 \mathrm{~m}$. hasta la mitad de las filas de los asientos y, de $10 \mathrm{~m}$., hasta los asientos situados cerca de la parodos ${ }^{92}$.

\footnotetext{
R. Sennet, op. cit., pp. 71-72.

bidem, p. 215.

Ibidem, pp. 56 y 65.
}

89 Vitruvio, op. cit.; G. A. Breyer, op. cit.; A. N. Modona, Gli edifizi Teatrali Greci e Romani, Firenze, Leo S. Olschki, 1961; R. Leacroft y H. Leacroft, Theatre and Playhouse. An Illustrated survey of Theatre Building from Ancient Greece to the present Day, New York, Methuen London Ltd, 1985; J. Onians, Arte y pensamiento en la época Helenistica, Madrid, Alianza, 1996, pp. 230 ss.

90 D. S. Robertson, Arquitectura Griega y Romana, Madrid, Cátedra, 1983, p. 164.

91 A. L. León Rodríguez, "La acústica de los teatros a través de la historia", en Actas del Segundo Congreso Nacional de Historia de la Construcción, ed. Bores, F., Fernández, J., Huerta, S., A Coruña, 22-24 octubre, pp. 263-271, 1998, aquí pp. 22-23.

92 L. Dyer y E. Sellers, "Theatre at Megalopolis", The Classical Review, vol. 5, nº 5, Cambridge University Press, 1891, p. 239. 
Por otra parte, los auditorios se pueden dividir, en general, en dos grandes grupos: los que poseen la acústica de una caverna y los que tienen acústica al aire libre y, si al parecer en los primeros nace la música, en los segundos lo hace el teatro ${ }^{93}$. Pues bien, la arquitectura teatral helena -que, desde mi perspectiva, es música y danza petrificada- parece compartir ambos modelos acústicos y no solo porque acoge espectáculos que incluyen la palabra, la danza y la música, sino también porque está construida al aire libre y porque la concavidad excavada en la montaña donde se sitúa la cavea recuerda a las grutas.

Así pues, existe una afinidad acústica y formal entre el teatro y las cuevas. A este respecto, conviene recordar que, en ocasiones, el edificio teatral se asocia a ellas, como ocurre con el de Dioniso en Atenas, situado al lado de la Gruta de Ariadna; con el de Delos o con el de Locros, conectado ritualmente con la Gruta Caruso donde también se hacen ciertas representaciones. Sin olvidar que, en las grutas redondas -o en los círculos sagrados-, se desarrollan ritos chamánicos en los que las palabras fluyen desde su interior con una funcionalidad mántica ${ }^{94}$. Mientras tanto, cerca de los templos, se ejecutan los sacrificios en los que se intercambian dones y oraciones con los dioses. Estos templos olímpicos, que están construidos al aire libre y abiertos a la luz del sol brillante, se distinguen de los santuarios de una deidad ctónica porque son espacios cerrados, una cueva o su réplica arquitectónica ${ }^{95}$.

Pues bien, entiendo que la arquitectura teatral constituye una forma híbrida, a medio camino entre el templo olímpico y la cueva ctónica, en la medida en que es tanto el reflejo del cielo como el eco de la caverna. De ahí que los espectadores de las representaciones dramáticas, por un lado, puedan comunicarse alto y claro con sus divinidades olímpicas celestes; y, por otro, escuchar los rumores apagados de los héroes, de los antepasados, de los viejos daimones y, en suma, del pasado, aunque también del presente reflexionado o cuestionado de la polis y de lo que está por-venir.

Es lo que ocurre en Delfos, donde la Sibila puede escuchar los estridentes crujidos de los ocasionales terremotos que se producen aquí y los más constantes balbuceos y silbidos de los vapores que salen del interior por un quicio de la tierra ${ }^{96}$ y que anuncian lo que está por acontecer: no en balde, el santuario está empotrado entre "retumbantes montañas"97. Pero lo importante es que el teatro de Delfos ejemplifica muy bien esta doble naturaleza celeste y ctónica y esa duplicada funcionalidad que cumple por ser recinto de plegaria y mántico-oracular. También lo hacen los de Dodona, Anfiareo y Epidauro. Dodona porque está dedicado al padre de los dioses olímpicos Zeus y a la Diosa Madre y porque en él se puede oír el anuncio de los dioses a través del susurro que las hojas de los robles producen al ser movidas por el viento ${ }^{98}$.

Anfiarao, por su parte, está consagrado al héroe argivo sanador, adivino y oracular que, en el combate desarrollado en los Siete contra Tebas, es tragado junto a su carro en la brecha abierta en la tierra por un rayo que envía Zeus. Puede, pues,

\footnotetext{
A. L. León, op. cit., p. 22.

94 E. Wilhelmsen, "San Juan de la Cruz: "Percepción" espiritual e Imagen poética", en Bulletin Hispanic, vol. 88, no 88, 3-4, 1986, pp. 293-319, aquí p. 313.

95 C. Ruck, "Lo silvestre y lo cultivado en la religión griega", en L. S. Rouner (ed.), Sobre la naturaleza, México, F.C.E., 1989 , p. 87.

96 R. Harris Díez, "Características del emplazamiento del templo griego", en htpp://lapetus.uchile.cl., s.a., p. 14.

97 G. Jellicoe, y S. Jellicoe, El paisaje del hombre. La conformación del entorno desde la Prehistoria hasta nuestros dias, Barcelona, Gustavo Gili, 2000, p. 121

98 S. Dakaris, Dodona, Ministry of Culture. Athens, Archaeological Receipts Fund, 1998, pp. 6 ss.
} 
imaginarse el llamativo contraste entre los ruidos atronadores de la guerra, del rayo y de la tierra que se abre y el atroz silencio que sigue al acontecimiento en el que el héroe viaja al subsuelo, al más allá. Por lo demás, en el templo del santuario -situado en Oropo- tiene lugar la incubación o enkoímesis, una ceremonia que recuerda a los ritos chamánicos y que permite a las personas que acuden allí, a través del sueño, curarse o recibir noticias de su futuro ${ }^{99}$. Igualmente cumple funciones incubatorias similares a las descritas el Santuario de Epidauro, dedicado al dios de la medicina Asclepio, hijo de Apolo.

En suma, en los teatros griegos, se pueden escuchar las voces de los humanos -vivos y muertos- y de los dioses y el murmullo o el grito de la naturaleza. Al mismo tiempo, estas construcciones se convierten en cavidades acústicas que recogen y reverberan los sonidos del pasado, del presente y del futuro. Ciertamente, tanto aquellos seres como el tiempo son invisibles a los ojos normales de la gente, pero el espectáculo dramático y el arrobamiento ante geografías míticas y paisajes excepcionales, al permitir a los espectadores un cierto grado de éxtasis y de catarsis -ecos lejanos de los viajes chamánicos-, facilita que en el interior de los edificios teatrales puedan experimentar una especie de incubación. Y es que, aunque se supone que estos participantes están bien despiertos durante la función diurna, su intensa entrega al transitorio mundo de la ficción es similar a la del sueño y, consecuentemente, pueden realizar un viaje de ida y vuelta desde la vida hacia la muerte y desde su sociedad hacia el mundo de la imaginación, y viceversa.

\subsection{La arquitectura teatral simboliza la triple geografía del cuerpo humano}

Ahora bien, la articulación de la arquitectura teatral con los mundos natural, divino y humano de la que vengo hablando no solo es acústica, ya que la euritmia antropomórfica -como ya he dicho- establece una analogía que relaciona las partes entre sí y a éstas con el todo. Así, la arquitectura teatral -al igual que el cuerpo humano, el $\operatorname{logos}^{100}$, el mundo sobrenatural o religioso ${ }^{101}$, el ốkos ${ }^{102}$, la aldea ${ }^{103}$, el urbanismo ${ }^{104} \mathrm{y}$ la polis $^{105}$ - deviene un sistema de relaciones y es articuladora, pues junta y no separa y concibe el espacio -en línea como lo hace la sociología urbana actual ${ }^{106}$ - como un atributo relacional. Particularmente, es el círculo central de la orchestra el que opone y ordena, a la vez, todo lo intrínseco de la estructura arquitectónica y a ésta con el espacio circundante.

Del mismo modo -al igual que sucede en el urbanismo heleno-, la arquitectura teatral se encuentra sometida a la tensión entre yuxtaponer los distintos elemen-

99 D. Hernández De La Fuente, Vidas de Pitágoras, Barcelona, Atalanta, 2011, pp. 41 y 88.

100 N. Bilbeny, Ética, Barcelona, Ariel, 2012, p. 86.

101 P. Lévêque, Bêtes, dieux et hommes. El imaginario de las primeras religiones, París, Éditions Messidor/Temps Actuels, 1985, p. 29.

102 E. M. Wood, "La Polis y el ciudadano-campesino", en El mundo rural en la Grecia antigua, J. Gallego, ed., Madrid, Akal, 2003, p. 316.

103 J. Gallego, "Comunidad aldeana y sociabilidad campesina en la Grecia Antigua", ibidem, pp. 335 y 375

104 B. Helly, "Le territoire de Larisa", en Ktema. Civilisations de l'Orient, de la Grèce et de Rome antiques, Université des Sciences Humanines, Strasbourg, nº 9, 1984, pp. 213-214.

105 E. Lledó Íñigo, Introducción a Platón, Diálogos, vol. I, Madrid, Gredos, 1985, p. 62.

106 J. Leal Maldonado, "Sociología del espacio: el orden espacial de las relaciones sociales", en Política y Sociedad, $\mathrm{n}^{\circ}$ 25, Universidad Complutense de Madrid, pp. 21-36, 1997, aquí p. 22. 
tos individuales - míxis- (lo que sucede, sobre todo, en los teatros más rústicos y antiguos: Tórico, Dioniso en Atenas, Argos, Queronea...) y ligar las partes entre sí formando un todo mediante unas relaciones estructuradas y jerarquizadas -sýnthesis-. El diseño vitruviano parecería indicar que esto se consigue plenamente en el teatro, pero en la práctica éste nunca logra una sýnthesis perfecta, ya que no consigue una unidad estructural arquitectónica. A lo más a lo que llega es a una armonía y geometría cuidadas, como sucede particularmente en los teatros de las ciudades planificadas o de los santuarios de Epidauro, Dodona, Arycanda, Mileto, Priene, Éfeso...

Así pues, el teatro se mueve entre la yuxtaposición o la sýnthesis de sus elementos, lo que no debe sorprender, pues en Grecia existe una fuerte yuxtaposición social presente, por ejemplo, en el inicio de las ciudades, ya que éstas son fruto de la yuxtaposición de unidades familiares vinculadas por relaciones de parentesco ${ }^{107}$. Igualmente se observa la míxis de los valores aristocráticos y del dêmos, así como de las ideologías tradicional y religiosa y racional y secular ${ }^{108}$. Finalmente, lo mismo ocurre con la míxis de lo religioso y de lo político en las ciudades y con los santuarios donde los edificios se yuxtaponen y se conectan solo visualmente ${ }^{109}$.

En todo caso, el diagrama del círculo y del cuadrado inscrito en la orchestra la vincula con las otras dos partes diferentes del teatro -la cavea y el edificio palcoescénico-, de manera que, a pesar de que no estén fundidas absolutamente en una misma estructura arquitectónica, al menos se interrelacionan a nivel funcional. Por eso, se puede decir -siguiendo a G. Simmel- que estos edificios no solo suponen el marco de la acción -dramática-, sino que representan asimismo "la condición y el símbolo de la relación entre los hombres"110, en este caso entre los actores y el coro y entre todos éstos y los espectadores. Más concretamente, la orchestra donde deambula el coro se conecta con el edificio palcoescénico en el que actúan los actores, al igual que lo hacen uno y otros a través de sus voces y de sus movimientos-acciones-. De esta manera, se ajustan tanto al espacio que los contiene como al género dramático en el que se producen: en la tragedia domina la palabra, mientras que en la comedia lo hace el movimiento ${ }^{111}$. A su vez, la orchestra, asociada con el edificio palcoescénico, queda interrelacionada también con la cavea donde se instalan los espectadores, del mismo modo que éstos responden con palabras, gestos o movimientos de aprobación o de rechazo al diálogo entre el actor y el coro.

Pero, como queda dicho, el edificio arquitectónico se convierte es algo más que un producto social, en la medida en que el espacio edificado -al igual que la aldea o la polis - constituye un sistema de relaciones sociales condicionado y condicionante, estructurado y estructurante ${ }^{112}$. No podía ser de otra manera si se quería que el

107 A. Lozano, “¿Segregación o integración?: Relaciones entre las ciudades griegas helenísticas de Asia Menor y las poblaciones anatólicas", en Gerión, vol. 20, n 1, Universidad Complutense de Madrid, 2002, pp. 205-230, aquí p. 206-226. P. Briant, "Villages et communautés villageoises d'Asie Achéménide et Hellénistique", en Journal of The Economic and Social History of The Orient, Vol. XVIII, Part II, 1975, pp. 167-188, aquí pp. 165-168.

108 F. Requejo Coll, Las democracias. Democracia antigua, democracia liberal y Estado de Bienestar, Barcelona, Ariel, 1990, pp. 44-57.

109 R. Harris, op. cit., pp. 12-13.

110 G. Simmel, Sociología: Estudio sobre las formas de socialización, Madrid, Revista de Occidente, 1924, p. 176.

111 M. Brioso Sánchez, "Sobre las convenciones escénicas de la tragedia y la comedia clásicas”, en M. Brioso Sánchez y A. Villarrubia Medina, (ed.), Aspectos del teatro griego antiguo, Universidad de Sevilla, 2005 ${ }^{\mathrm{a}}$, p. 186.

112 J. Leal Maldonado, op. cit., pp. 27-30. 
espectáculo dramático fuera percibido por los asistentes en su unidad, si se deseaba que el cuerpo individual y el de la polis quedaran imbricados el uno en el otro y si se trataba de que los diversos roles cívicos no impidieran la unidad de la polis, el gran ideal del pueblo griego.

En este sentido, la arquitectura teatral -analogía de la polis- sigue el carácter centrípeto de las ciudades modeladas según el pensamiento cosmogónico igualitario de Anaximandro ${ }^{113}$, pero sin olvidar la religiosidad implícita en el mismo. Así, el altar u ombligo -la thýmele-, dispuesto generalmente en la posición central de la orchestra, es justamente lo que constituye el núcleo del diagrama del círculo y del cuadrado y del carácter articulador del teatro heleno. La thýmele hace de eje de los tres niveles o geografías que, desde los tiempos más remotos, dividen el universo mítico (la tierra como un disco plano con raíces descrito por Homero o por Hesíodo; lo alto, el cielo, el espacio de Zeus y de los dioses inmortales; lo de en medio, la tierra, el territorio de los humanos; y, lo bajo, el submundo, el dominio de la muerte y de los dioses del subsuelo ${ }^{114}$. Por eso, precisamente debajo de la orchestra se halla, en algunas ocasiones (Sición, Eretria y Argos), un pasaje o pasillo subterráneo, un espacio dedicado al submundo y a la muerte, presencia no visible pero constante cuando los coros pasean por encima del suelo de la orchestra.

\section{A modo de conclusiones}

Como se ha visto en este artículo, la arquitectura teatral ha sido entendida por los griegos como un cuerpo-signo que significa, pues está construida por ellos social, cultural y políticamente a la manera de reflejo y creadora del orden social. Así, podemos considerarla como un microcosmos de su concepción del mundo y, en definitiva, como un exponente clarividente de una de las civilizaciones más excelsas del planeta.

1. Más concretamente, se ha podido demostrar, en primer lugar, que el edificio teatral representa un cuerpo articulado cósmico, masculino y femenino que ve, oye y habla. Cósmico porque se convierte en un monumental edificio imbricado, formal y estructuralmente, en el paisaje natural -domesticado y divinizado-y urbano y, por consiguiente, en un símbolo de la naturaleza, de la divinidad y del ser humano político, esto es, en un microcosmos de la cosmovisión helena. No en balde, el cosmos es entendido por los griegos como un ser racional e inteligente y como un organismo vivo en el que todas sus partes se unen por simpatía.

Pero si el cuerpo del edificio teatral está conectado con el universo entero, si constituye una analogía del cosmos, también lo es del cuerpo humano. Esto explica que el diagrama del círculo y del cuadrado, base del diseño del edificio teatral, manifieste, a la vez, las órbitas celestiales -el círculo-y la "cuadrada" solidez de la tierra, de modo que el cuerpo humano fusiona, en sí mismo, las diversidades del cielo y de la tierra, el deseo de los individuos de fundirse con el todo, de reintegrarse en el orden cósmico general.

Por consiguiente, la antropometría o la euritmia antropométrica, que modela todo el organismo teatral, remite a un ser humano ambivalente, es decir, al mismo tiempo

113 J-P. Vernant, Mito y pensamiento en la Grecia Antigua, Barcelona, Ariel, 1993, pp. 187-193; J-P. Vernant, Mito y pensamiento en la Grecia antigua, Barcelona, Ariel, 1983, pp. 187 ss y 227 ss.

114 bidem, pp. 186-187 y 235. 
terrestre y celeste - como ya se ha visto-, sagrado y profano o religioso y político y masculino y femenino. Religioso y profano porque, si el propio edificio personifica esculturalmente el carácter del dios y de su presencia -la estatua del dios en la thýmele es testigo de ello-, también lo hace de los humanos orantes que, con su propio cuerpo, generan -al igual que en los templos- una imagen determinada del dios o, lo contrario, su convicción de que son parientes de los dioses ${ }^{115}$. Asimismo, el cuerpo arquitectónico teatral es tanto masculino como femenino, puesto que está edificado al aire libre -al igual que los cuerpos desnudos de los hombres- y ya que la feminidad de la analemma le sirve de protección, la de las puertas le abren y paren el mundo y la de la phallophoria o procesión que "penetra" triunfalmente en el recinto de la pradera-orchestra le facilitan la hierogamia y la celebración de la fertilidad natural y, en suma, la relación sexual entre dos cuerpos -el masculino y el femenino-.

Pero ambos cuerpos quedan también fusionados mediante la dialéctica que el edificio teatral establece entre lo vertical y lo horizontal, pues las dos disposiciones simultáneas simbolizan, respectivamente, la mezcla de lo masculino y lo femenino, la bisexualidad, el carácter hermafrodita o andrógino, el matrimonio del marido y de la esposa y la unidad funcional del hombre y de la mujer, tan necesaria en una sociedad agrícola y autosuficiente. En todo caso, esta posición vertical y horizontal del teatro construye una metáfora de un cuerpo humano que está tumbado en la tierra -la orchestra y el edificio palcoescénico- y recostado sobre la ladera de una colina -la cavea-. No se olvide que, si -como ha dicho Vitruvio- el teatro constituye una analogía del propio cuerpo humano en tanto que dibuja un cuadrado perfecto que abarca todo el cuerpo al tiempo que las manos y los pies desplazados tocan un círculo centrado en el ombligo, esto puede llevar a inferir que la "cabeza" de ese cuerpo arquitectónico lo representa justamente la cavea, mientras que el resto del cuerpo y los pies serían la orchestra y el edifico palcoescénico.

Finalmente, la arquitectura teatral encarna un cuerpo humano articulado por su preocupación por el ojo que contempla y por la voz y el oído que habla y escucha. Desde luego, la visión constituye el "órgano" principal del edificio y de las funciones que cumple -el Théatron, el theōrós-, pero la acústica supone también un complemento sustancial y no cabe duda de que constituye un factor esencial en su evolución. $\mathrm{Si}$-como se ha dicho- existen dos modelos acústicos de edificios para los espectáculos -el de la acústica de una caverna y el de la acústica al aire libre-, la arquitectura teatral, que es música, danza y palabra petrificada, parece compartir ambos modelos porque la concavidad excavada en la montaña donde se sitúa la cavea recuerda a las grutas y porque existe una afinidad acústica y formal entre el teatro y las cuevas. En este sentido, puede pensarse que el teatro es una forma híbrida, a medio camino entre el templo olímpico y la cueva ctónica, esto es, un reflejo del cielo y un eco de la caverna. Al menos, es lo que ejemplifican los teatros de Delfos, Anfiareo y Dodona, caracterizados por su doble naturaleza celeste y ctónica, por ser recinto de plegaria y mántico-oracular. En cualquier caso, en los teatros griegos se visibiliza lo invisible a los ojos normales de la gente, pues se pueden escuchar las voces de los humanos -vivos y muertos- y de los dioses y el murmullo o el grito de la naturaleza, al igual que los sonidos del pasado, del presente y del futuro. Ello es así porque el éxtasis y la catarsis de los espectáculos dramáticos -ecos lejanos de los viajes chamánicos- permiten que los espectadores, en el interior de los recintos tea-

115 K. Vossler, Jean Racine, Buenos Aires, Espasa Calpe, 1946, pp. 122-124. 
trales, experimenten una especie de incubación, un sueño despierto que constituye un viaje de ida y vuelta desde la vida hacia la muerte y desde la polis y la sociedad hacia el mundo de la imaginación, y viceversa.

2. En segundo lugar, la arquitectura teatral personifica la triple geografía en la que habita el cuerpo humano. Lo hace, en principio, porque el edificio teatral manifiesta una tensión entre la yuxtaposición de los distintos elementos individuales -míxis-o el ligamento de las partes entre sí formando un todo mediante unas relaciones estructuradas y jerarquizadas -sýnthesis-. Y, aunque no logra una sýnthesis perfecta en tanto que no consigue una unidad estructural arquitectónica, sí alcanza la míxis de los valores aristocráticos y del dêmos, de las ideologías tradicional y religiosa y racional y secular, de la vida urbana y campesina y de lo religioso y lo político. Además, deviene un sistema de relaciones condicionado y condicionante, estructurado y estructurante y la condición y el símbolo de la relación entre los humanos, o lo que es lo mismo, un "atributo relacional", un órgano articulador en el que el círculo central de la orchestra opone y ordena, a la vez, la estructura arquitectónica y a ésta con el espacio circundante. No extrañe que, en el exterior del edificio, queden vinculados estética y simbólicamente la polis, el teatro y el entorno natural y que, en su interior, se hallen conectados entre sí los actores y el coro y todos éstos y los espectadores. Esto quiere decir que el cuerpo humano, raíz de la medida y metáfora fundamental del diseño del teatro, es tanto individual como colectivo, o mejor, es el de un individuo plenamente insertado en su polis y en el cosmos. Así, la arquitectura teatral logra exhibir el gran ideal del pueblo griego: la búsqueda de la unidad. Una unidad de tipo ideal, contrastada y elevada sobre la realidad, que no siempre es tan armónica.

Por otro lado, el carácter centrípeto del edificio teatral-similar al de las poleis modeladas según el pensamiento cosmológico y político de Anaximandro- permite que el altar u ombligo del edificio -la thýmele-, ubicada en la posición central de la orchestra en una gran parte de los teatros, constituya el verdadero núcleo del diagrama del círculo y del cuadrado y, en definitiva, del carácter articulador del teatro. Al respecto, no es gratuito que la thýmele haga de eje horizontal y vertical de los tres niveles o geografías que dividen el universo mítico griego: lo alto, el cielo, el espacio de Zeus y de los dioses inmortales; lo de en medio, la tierra, el territorio de los humanos; y lo bajo, el submundo y la muerte.

De este modo, la thýmele-altar-ombligo se convierte en el centro del cuerpo humano y del cuerpo cósmico, los dos fundamentos del diseño y del significado de la arquitectura teatral, lo que manifiesta que ésta está condicionada, al mismo tiempo, por lo físico, por lo estético, por lo político y por el roce con lo trascendente y con lo metafísico. Así se entiende que la arquitectura teatral encarne una figura humana tumbada sobre la tierra y reclinada sobre la montaña, con los pies en el suelo y con la vista puesta en el firmamento y revela el que posiblemente sea el trasunto más hondo de la misma: que el cuerpo humano del que nos habla es ciertamente sensitivo, carnal, corporal y, por consiguiente, mortal, pero posee también ciertas aspiraciones a la inmortalidad. Esto es coherente con lo que dice Vitruvio, que la arquitectura de los griegos está construida para "eterna duración y permanencia", aunque eso sí -añadiría yo, para finalizar- constituye igualmente una frágil huella de las desesperadas plegarias y oraciones de los mortales que claman contra su absurda condición. Sus murmullos, apenas audibles, han logrado, sin embargo, rebotar en las piedras de los edificios, extenderse por el conjunto del paisaje y del firmamento y llegar como un eco lejano a nosotros. 